\title{
Interactive comment on "Resolving the size of ice-nucleating particles with a balloon deployable aerosol sampler: the SHARK" by Grace C. E. Porter et al.
}

\section{Anonymous Referee \#2}

Received and published: 28 January 2020

In this paper, the authors describe the SHARK platform to measure the aerosol size and to sample the aerosols for INP analysis. The platform also deploys meteorological sensors. Size-resolved aerosol and INP measurements within the boundary layer are missing, and I think such a platform in the future can be very useful. The paper is well written. I have a few minor comments that I suggest the authors address before the paper can be published.

The importance of aerosol composition towards INP efficiency should be mentioned. Although size is important for transport/dispersion and residence time within the atmosphere; it should be noted that INP efficiency in addition to the size also depends upon 
the other factors (e.g., composition: e.g., organics vs. dust, particle type: e.g., spherical vs. non-spherical, etc.). Currently, it reads like size is the most important factor that AMTD determines the INP efficiency.

It should be acknowledged that the SHARK technique does not provide spatial and temporal measurements of INP.

It is not clear regarding the use of equation 3 to calculate Ns. Fice and $\mathrm{N}$ are determined using different techniques. It is not clear how the measurements from both techniques can be combined. $\mathrm{N}$ quantity (line 414 ) is the total number of particles, which depends upon the volume of air sampled, duration time, and some particle concentration $(\# / c c)$. Is it possible that the number of particles that enter the impactor (section 3.2) might be different than OPC (line 415) because of losses within the impactor?

Interactive comment on Atmos. Meas. Tech. Discuss., doi:10.5194/amt-2019-457, 2019. 